\title{
Preface for Tempmeko \& ISHM 2010
}

\author{
Joachim Fischer • Jeremy Lovell-Smith
}

Published online: 10 November 2010

(C) Springer Science+Business Media, LLC 2010

The first TEMPMEKO \& ISHM joint international symposium on temperature, humidity, moisture, and thermal measurements was held from May 31st to June 4th, 2010 in Portorož, Slovenia. This joint event was agreed to following the previous editions of the conferences, namely, the 10th International Symposium on Temperature and Thermal Measurements in Industry and Science, an event known as TEMPMEKO 2007, in Lake Louise, Canada in 2007 and the 5th International Symposium on Humidity and Moisture, an event known as ISHM 2006, in Rio de Janeiro, Brazil in 2006.

The TEMPMEKO Symposia are organized under the auspices of Technical Committee 12 (TC12) of the International Measurement Confederation (IMEKO), with responsibility for temperature and thermal measurements. The first event was held in 1981 in Karlovy Vary (Czechoslovakia), followed by events in Suhl (East Germany, 1984), Sheffield (United Kingdom, 1987), Helsinki (Finland, 1990), Prague (Czech Republic, 1993), Torino (Italy, 1996), Delft (The Netherlands, 1999), Berlin (Germany, 2001), and Dubrovnik-Cavtat (Croatia, 2004). Further information on IMEKO and TC12 is available at www.imeko.org/tc12.

The ISHM symposia are convened by Consultative Committee for Thermometry Working Group 6 on Humidity Measurements (CCT/WG6) of the International Committee on Weights and Measures (CIPM). The first ISHM event was held in 1963 in Washington, DC, USA, under the auspices of the US National Bureau of Standards, Instrument Society of America, and others. This was followed by events in Washington DC (1985), London (UK, 1998), Taipei, (Taiwan, 2002), and Rio de Janeiro (Brazil,

\footnotetext{
J. Fischer $(\varangle)$

Physikalisch-Technische Bundesanstalt, Abbestrasse 2-12, 10587 Berlin, Germany e-mail: joachim.fischer@ptb.de

J. Lovell-Smith

Measurement Standards Laboratory, Industrial Research Limited, P.O. Box 31310, Lower Hutt 5040, New Zealand
} 
2006). Further information on CIPM Consultative Committee for Thermometry and Working Group 6 can be found at http://www.bipm.org/en/committees/cc/cct/.

TEMPMEKO \& ISHM 2010 was organized by the University of Ljubljana, Faculty of Electrical Engineering, Laboratory of Metrology and Quality and the Slovenian Society for Process Control and Measurements, the Member Organization of IMEKO from that country, in close co-operation with the Metrology Institute of the Republic of Slovenia. The 303 attendees came from 49 countries and represent a significant increase when compared to previous events. This can be attributed to the decision to hold a joint event as well as to the convenient location. Geographically, there were 204 participants from Europe, 52 from the Asia-Pacific region, 36 from the Americas, and 11 from Africa.

The conference began with a welcome party on Sunday evening, May 31st, that was an informal mixer for friends and colleagues to renew acquaintances. The conference program ran from Monday morning to Thursday evening. Participants were able to spend time together outside the scientific program, sharing meals, coffee breaks, and social events. On Wednesday afternoon a cultural visit took place to the Predjama castle and to the world famous Postojna cave, followed by a dinner in front of the cave. The Thursday Conference dinner marked the closing of TEMPMEKO \& ISHM 2010 .

Over the 4 days of the conference, the participants delivered 138 oral and 206 poster presentations, including five plenary talks. The oral presentations occupied 33 sessions, with the majority of these taking place in three parallel streams. Among them were dedicated sessions on the determination of the Boltzmann constant and on the "mise en pratique" for the definition of the kelvin marking new horizons in thermometry. Other well-supported sessions in the field of temperature and thermal measurements covered the development of high-purity and eutectic fixed points and new radiation thermometry issues. In the humidity and moisture field, the plenary presentation outlining the ambitious and successful 2010 thermodynamic equation of seawater (TEOS-10) complemented oral and poster presentations of new determinations of vapor pressure, of new and improved methods of generating and measuring humidity, and presentations exploring traceability in the measurement of moisture and other thermodynamic quantities. The posters were divided into three separate sessions on Monday, Tuesday, and Thursday. The posters were conveniently placed among the exhibitors and were accessible throughout the day. Taking advantage of the large participation, several other technical meetings took place during and after the joint event.

An exhibition of temperature and humidity measuring equipment from 13 companies (Automatic Systems Laboratories, Fluke Corporation (Hart Scientific Division), Guildline Instruments, INSCO, Isotech-Isothermal technology, Kambič Laboratory Equipment, MBW Calibration and RH Systems, Measurements International Ltd., Mettler Toledo, Michell Instruments, Pond Engineering, Rotronic, Vaisala) took place adjacent to the lecture rooms, and conference participants were encouraged to take the opportunity to view the exhibits and speak with the representatives in attendance. We are grateful for the exhibitors' support of TEMPMEKO \& ISHM 2010, and wish to give special thanks to Fluke Corporation (Hart Scientific Division), Isotech, Kambič Laboratory Equipment, Tiger Optics, Vötsch Industrietechnik, MBW Calibration, and 
RH Systems for sponsoring various social events and meals during the week. This allowed us to provide a much "richer" experience for the participants than would otherwise have been possible without significantly increasing the registration fee.

It is a pleasure to acknowledge the expertise and dedication of the many individuals who contributed to the successful organization of the Symposium and to the preparation of these special issues. Among those are the authors, the chairs of the sessions, and especially the referees of the papers, who had to cope with an extremely high workload due to the high number of submitted manuscripts. In total some 220 manuscripts from the field of temperature and thermal measurements and nearly 50 manuscripts from the field of humidity and moisture could be selected for special issues of TEMPMEKO \& ISHM 2010, marking an increase compared to earlier events. We are grateful to the local organizers of the conference: Janko Drnovšek, Igor Pušnik, and Jovan Bojkovski gave us every logistic support required for developing the scientific program. We are indebted to Stephanie Bell of the steering committee and Francesco Righini, chair of IMEKO TC12, for her/his encouragement and support throughout the past 3 years, and to Mickey Haynes for guiding us through the editorial process. Editing the special issues of selected TEMPMEKO \& ISHM 2010 contributions was demanding work but we hope the readers will agree that the effort was worthwhile.

Last but not least, we send to the colleagues at the Portuguese institute for Quality (IPQ) our best wishes for a successful TEMPMEKO 2013 in Madeira. 